\title{
Vitamin D and susceptibility of chronic lung diseases: role of epigenetics
}

\section{Isaac K. Sundar and Irfan Rahman*}

Lung Biology and Disease Program, Department of Environmental Medicine, University of Rochester Medical Center, Rochester, NY, USA

\section{Edited by:}

Masakazu Ichinose, Wakayama

Medical University, Japan

Reviewed by:

Koichiro Asano, Keio University

School of Medicine, Japan

Kazuhiro Ito, Imperial College, UK

${ }^{*}$ Correspondence:

Irfan Rahman, Lung Biology and

Disease Program, Department of

Environmental Medicine, University

of Rochester Medical Center, Box

850, 601 Elmwood Avenue,

Rochester, NY 14642, USA.

e-mail: irfan_rahman@urmc.rochester. edu
Vitamin D deficiency is linked to accelerated decline in lung function, increased inflammation, and reduced immunity in chronic lung diseases. Epidemiological studies have suggested that vitamin D insufficiency is associated with low lung function in susceptible subjects who are exposed to higher levels of environmental agents (airborne particulates). Recent studies have highlighted the role of vitamin D and vitamin D receptor (VDR) in regulation of several genes that are involved in inflammation, immunity, cellular proliferation, differentiation, and apoptosis. Vitamin D has also been implicated in reversal of steroid resistance and airway remodeling, which are the hallmarks of chronic obstructive pulmonary disease (COPD) and severe asthma. VDR protein level is decreased in lungs of patients with COPD. VDR deficient mice develop an abnormal lung phenotype with characteristics of COPD, such as airspace enlargement and decline in lung function associated with increased lung inflammatory cellular influx, and immune-lymphoid aggregates formation. Dietary vitamin $D$ may regulate epigenetic events, in particular on genes which are responsible for COPD susceptibility. Active metabolite of vitamin D, 1,25-dihydroxyvitamin $\mathrm{D}_{3}$ plays an essential role in cellular metabolism and differentiation via its nuclear receptor (VDR) that cooperates with several other chromatin modification enzymes (histone acetyltransferases and histone deacetylases), thereby mediating complex epigenetic events in vitamin $\mathrm{D}$ signaling and metabolism. This review provides an update on the current knowledge and understanding on vitamin $\mathrm{D}$, and susceptibility of chronic lung diseases in relation to the possible role of epigenetics in its molecular action. Understanding the molecular epigenetic mechanism of vitamin DNDR would provide rationale for dietary vitamin D-mediated intervention in prevention and management of chronic lung diseases linked with vitamin $D$ deficiency.

Keywords: vitamin $\mathrm{D}$ receptor, vitamin $\mathrm{D}$, air pollutants, inflammation, epigenetics, asthma, COPD

\section{INTRODUCTION}

In recent years, vitamin $\mathrm{D}$ insufficiency has been on the rise in general population throughout the world (Ginde et al., 2009). Vitamin D deficiency is linked to decline in lung function, increased inflammation, and reduced immunity (Janssens et al., 2009; Litonjua, 2009; Kumar et al., 2011). Epidemiological studies have further suggested that vitamin D insufficiency is associated with poor lung function in susceptible populations, particularly in patients with asthma and chronic obstructive pulmonary disease (COPD; Gilbert et al., 2009; Chishimba et al., 2010; Forrest and Stuhldreher, 2011; Kunisaki et al., 2011) who are exposed to higher levels of air pollutants (airborne particulates). These susceptible individuals may develop frequent exacerbations, rapid decline in lung function, and exercise capacity (Ferrari et al., 2010; Janssens et al., 2010; Newnham et al., 2010; Hansdottir and Monick, 2011).

Recent studies have shown that vitamin $\mathrm{D}$ has pleiotropic protective effects (Lin and White, 2004; Chishimba et al., 2010). $1,25(\mathrm{OH})_{2} \mathrm{D}_{3}$ (1,25-dihydroxyvitamin $\left.\mathrm{D}_{3}\right)$, an active metabolite of vitamin $\mathrm{D}$ is also a potent regulator of the immune response in
Th1 cell-directed diseases (Cantorna, 2000; White, 2008). Ligand binding activates vitamin D receptor (VDR), a steroid hormone superfamily of nuclear receptors, which then binds to specific genomic sequences in the promoter regions of target genes (vitamin D response elements), and thus recruits transcription factors and co-regulatory molecules on promoters to activate or suppress gene transcription (Dusso, 2003). Therefore, it is possible that epigenetic chromatin remodeling events might be important in the regulation of vitamin D-mediated gene expression involved in various cellular functions. We have recently shown that VDR deficiency invokes lung inflammation and alterations in lung function (Sundar et al., 2011). Hence, understanding the molecular mechanisms of dietary vitamin D for the treatment of lung disease and their exacerbations are an emerging area of research (Lehouck et al., 2011). The aim of this review is to highlight the immuneinflammatory responses linked to epigenetic chromatin alterations by dietary vitamin $\mathrm{D}$, and the importance and role of dietary vitamin $\mathrm{D}$ in modulating chronic lung diseases augmented by exposure to cigarette smoke and environmental agents (airborne particulates). 


\section{VITAMIN D DEFICIENCY AND LUNG FUNCTION}

The active form of vitamin $\mathrm{D}, 1,25(\mathrm{OH})_{2} \mathrm{D}_{3}$ (1,25-dihydroxyvitamin $D_{3}$ ) is critical for immune regulation, and deficiency of vitamin $\mathrm{D}$ has been linked to several chronic diseases in susceptible population exposed to airborne particulates (Cantorna, 2000; Bouillon et al., 2008b; Dogan et al., 2009; Herr et al., 2011). Janssens et al. (2011) explained several interesting aspects on the role of vitamin $\mathrm{D}$ in COPD, such as the prevalence and determinants of vitamin D deficiency in COPD, role of vitamin D in COPD and osteoporosis, vitamin D pathway linking airways and systemic inflammation in COPD. Furthermore, several recent studies have correlated the dietary status of vitamin $\mathrm{D}$ with the pathogenesis of chronic lung diseases, such as the COPD and asthma (Janssens et al., 2009; Sutherland et al., 2010; Herr et al., 2011; Kumar et al., 2011). The Third National Health and Nutrition Examination Survey (NHANES) study showed a strong relationship between serum levels of 25-hydroxyvitamin D and pulmonary function, as assessed by $\mathrm{FEV}_{1}$ and FVC in susceptible US populations living in urban areas (Black and Scragg, 2005). Another cross-sectional study from Spain in hospitalized adult COPD patients revealed the similar results on decreased vitamin $\mathrm{D}$ intake based on dietary assessment of vitamin D status (De Batlle et al., 2009). However, a recent study reported by Shaheen et al. in an older adult UK population (the Hertfordshire Cohort study) did not show a positive correlation between serum $25(\mathrm{OH}) \mathrm{D}$ concentrations (dietary vitamin $\mathrm{D}$ intake) and lung function in spirometrically defined COPD patients. This study concluded that vitamin $\mathrm{D}$ is not an important determinant of adult lung function or COPD in the general UK population (Shaheen et al., 2011).

Vitamin D-binding protein has immunomodulatory functions pertinent to the lung, and is associated with activation of macrophages and neutrophil chemotaxis (Chishimba et al., 2010; Wood et al., 2011). Several reports have shown the functional relevance of vitamin D-binding protein gene (GC; group-specific component) polymorphism association with COPD (Schellenberg et al., 1998; Ohkura et al., 2006; Janssens et al., 2010). Furthermore, recent epidemiological reports have emphasized the association of low serum levels of vitamin D in severe asthmatics and COPD patients with steroid use, and patients with reduced glucocorticoid response (Franco et al., 2009; Janssens et al., 2009; Searing et al., 2010). However, the role of dietary vitamin D supplementation in response to cigarette smoke and environmental agents (airborne particulates) on lung mechanics/functions and lung immune-inflammatory cellular regulation via epigenetic chromatin modifications is less understood.

\section{VITAMIN D REGULATION OF IMMUNE AND INFLAMMATORY RESPONSES IN CHRONIC LUNG DISEASES}

Smoking alters vitamin D metabolism in the lungs (Hansdottir et al., 2010b), and dietary vitamin D regulates several genes that are involved in immune response, inflammation, cellular proliferation, differentiation, and apoptosis (Holick, 2007; Figure 1). Recent studies have highlighted the physiological implications of vitamin D intake/supplementation to improve innate immune response against respiratory pathogens as well as to enhance respiratory health in subjects with vitamin D deficiency/ insufficiency (Holick and Chen, 2008; Hughes and Norton, 2009).
$1,25(\mathrm{OH})_{2} \mathrm{D}_{3}$ is a direct regulator of antimicrobial peptides, such as cathelicidin (camp) and defensin $\beta 2$ (defß2) genes that are driven by vitamin D response elements (VDRE)-containing promoters, revealing the potential therapeutic role of vitamin $\mathrm{D}_{3}$ analogs against opportunistic infections, including the infections in the respiratory tracts which occurs in patients with COPD susceptible to exacerbations (Wang et al., 2004). The active vitamin D generated in the lung plays a vital role in pulmonary immune response. Vitamin D in airway epithelium regulates VDR-mediated gene expression to recognize and kill pathogens via a mechanism involving the TLR co-receptor CD14 and antimicrobial peptides (Hansdottir et al., 2008). Furthermore, during the viral infection in airway epithelium, 1,25D (1,25-dihydroxyvitamin D) modulates the expression of NF- $\kappa \mathrm{B}$-mediated inflammatory chemokines and cytokines (Hansdottir et al., 2010a). VDR deficient (VDR ${ }^{-/-}$) mice showed resistance to LPS-induced airway inflammation even though pathogenic $\mathrm{T}$ cells were primed and activated which supports the fact that $1,25(\mathrm{OH})_{2} \mathrm{D}_{3}$ and VDR in the lung play an important role in response to inflammatory signals mainly, the innate immune response (Wittke et al., 2007). $\mathrm{VDR}^{-/-}$mice failed to develop airway inflammation and airway hyperresponsiveness, suggesting that vitamin D could play an important role in Th2-driven lung inflammation (Wittke et al., 2004, 2007).

The levels of VDR are shown to be significantly lower in the lung tissues from patients with COPD compared with smokers (Sundar et al., 2011). The lung phenotypic, physiological characteristics, and associated key signaling molecules, and respiratory mechanics are recently studied in the lungs of $\mathrm{VDR}^{-/-}$mice (Sundar et al., 2011). $\mathrm{VDR}^{-/-}$mice showed a significant increase in neutrophil influx in BAL fluid and increased macrophage influx into the lung interstitium compared to WT mice (Sundar et al., 2011). The progression of COPD severity has been associated with cellular infiltration of inflammatory immune cells in the small airways. Vitamin D functions to generate anti-inflammatory cytokines to protect the host environment against invading microbes from the external environment (Adams and Hewison, 2008). 1,25( $\mathrm{OH})_{2} \mathrm{D}$ is produced by the VDR-macrophage interaction to modulate innate immunity against microbial agents. VDR-expressing $\mathrm{T}$ and B-lymphocytes modulate adaptive immunity, thus minimizing inflammation and autoimmune diseases (Adorini et al., 2004; Liu et al., 2006; Adams and Hewison, 2008). This may have implications in severity or exacerbations of asthma and COPD.

Neutrophilic granulocytes and macrophages, which belong to the innate immune system, are the key inflammatory cells that are known to play an important role in the pathogenesis of COPD. This has been confirmed by several animal studies demonstrating the importance of these immune cells in the induction and development of cigarette smoke-mediated chronic lung inflammation and emphysema (Yao et al., 2008; Rajendrasozhan et al., 2010). Several studies have highlighted the facts that the progression and severity of COPD are associated with increasing cellular infiltration of airways by innate and adaptive inflammatory immune cells (polymorphonuclear leukocytes, macrophages, lymphocyte subtypes $\mathrm{CD}^{+}$and $\mathrm{CD}^{+} \mathrm{T}$ cells, and B-lymphocytes). These immune-inflammatory cells form an aggregate as large volume together with the pool of inflammatory cells as lymphoid follicles in severe cases of COPD (Hogg et al., 2004; van der 


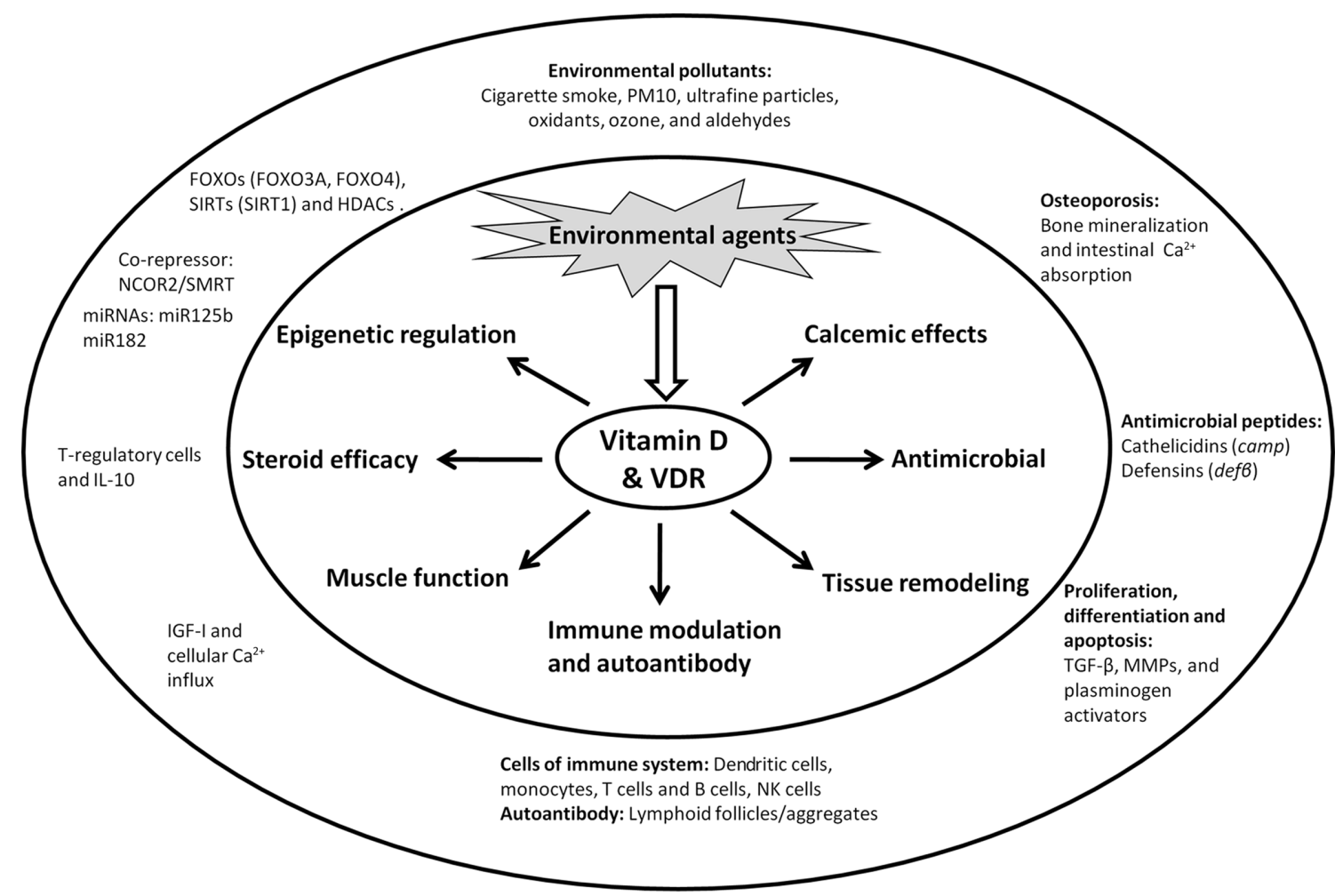

FIGURE 1 | Role of vitamin D/VDR in environmental agent-mediated deregulation of cellular and molecular functions. Environmental agents such as cigarette smoke, particulate matter (less than $10 \mu \mathrm{m}, \mathrm{PM10}$ ), ultrafine particles, inhaled oxidants, ozone, and aldehydes activate vitamin $D$ receptor and affects different downstream cellular and molecular targets as a result of vitamin D-mediated deregulation. The major cellular and molecular function affected due to vitamin DNDR deregulation includes: calcemic effects, antimicrobial peptide gene activation, tissue remodeling, immune modulation and autoantibody production, muscle function, steroid efficacy, and epigenetic regulation.
Strate et al., 2006). All of these processes including regulation of innate immune as well as inflammatory responses are regulated by vitamin D (Figure 1).

Pulmonary inflammatory response (infiltration of neutrophils and macrophages) plays a central role in the etiology of COPD as evidenced in emphysematous lung of smokers and mouse exposed to cigarette smoke showing airspace enlargement (Barnes et al., 2003; Yao et al., 2008; Rajendrasozhan et al., 2010). Immuneinflammatory cells release numerous mediators that can cause airway constriction and remodeling. These cells also produce proteases (elastases, cathepsins, granzymes, and MMPs) that could destroy the lung parenchyma. Changes in the levels of these mediators are associated with activation of NF- $\kappa \mathrm{B}$ in the lung (Caramori et al., 2003; Rajendrasozhan et al., 2008). Site-specific post-translational modifications (PTMs), such as phosphorylation and acetylation of RelA/p65 play an important role in the activation of NF- $\kappa \mathrm{B}$ and cigarette smoke-mediated lung inflammation (Chen et al., 2005; Yang et al., 2007). The role of VDR in regulation of inflammation has been recently demonstrated using the VDR deficient mouse embryonic fibroblast cells. Ablation of VDR leads to reduction in the protein levels of $\mathrm{I} \kappa \mathrm{B} \alpha$ through protein translation, protein-protein interaction, PTMs, and degradation by the proteasome, thereby providing a new insight into the VDR regulation as an inhibitor of NF- $\mathrm{B}$ in inflammation (Wu et al., 2010b). Recently, Wu et al. (2010a) has demonstrated the direct involvement of intestinal VDR in suppression of bacteria-induced $\mathrm{NF}-\kappa \mathrm{B}$ activation. Thus, VDR plays an important role in maintaining intestinal homeostasis and in protecting host against bacterial invasion and infection. The exact role of VDR in relation to NF$\kappa \mathrm{B}$ signaling still remains unclear (Sun et al., 2006). $\mathrm{VDR}^{-/-}$mice showed site-specific PTMs of NF- $\mathrm{B}$ RelA/p65, increased NF- $\mathrm{B}$ dependent pro-inflammatory cytokines (MCP-1 and $\mathrm{KC}$ ) release as well as an imbalance in levels and activities of MMPs and tissue inhibitors of metalloproteinases (TIMPs) that are potentially involved in alveolar destruction (emphysema) and extracellular matrix remodeling in the lung (Sundar et al., 2011). Earlier studies in the heart of $\mathrm{VDR}^{-/}$mice have demonstrated a significant increase in MMP-2 and MMP-9 mRNA levels (Rahman et al., 2007; Simpson et al., 2007). Increased MMPs enzyme activity along with collagen deposition, contribute to cellular hypertrophy and lung fibrosis. Vitamin D modulates the expression and metabolism of extracellular matrix genes in $\mathrm{VDR}^{-1-}$ mice (Rahman et al., 2007; Simpson et al., 2007). In an earlier report, $1,25(\mathrm{OH})_{2} \mathrm{D}$ deficiency in Klotho mutant mice with emphysema phenotype showed, skin atrophy, and osteoporosis (Razzaque et al., 2006). Therefore, it is speculated that vitamin D deficiency negatively affects lung extracellular matrix formation and leads to cellular senescence phenotype or smoke-induced emphysema (Black and Scragg, 2005). Based on earlier studies, TIMPs and MMPs play a vital role in sacculation and alveologenesis due to the fact that 
several MMPs and all the four TIMPs (i.e., TIMP1-4) are differentially expressed during various stages of lung development (Nuttall et al., 2004; Greenlee et al., 2007). MMPs and TIMPs are differentially regulated in VDR deficient mice. Furthermore, the genes of these enzymes are regulated by chromatin modifications. $1,25-(\mathrm{OH})_{2} \mathrm{D}$ directly or indirectly modulates extracellular matrix homeostasis in tissues apart from bone, particularly in the lung and skin tissue using the control of transforming growth factor- $\beta$ (TGF- $\beta$ ), MMPs, and plasminogen activators (Koli and Keski-Oja, 1996; Boyan et al., 2007). The reason for development of increased airspace enlargement or reduced alveologenesis/alveolar septation via epigenetic alterations of developmental genes if any, in $\mathrm{VDR}^{-/-}$ mouse remains unclear. Furthermore, the studies are needed to understand the role of VDR in lung development over a time course from post-partum day 1 (PP1) through PP14.

\section{VITAMIN D REGULATION IN CO-MORBID CONDITIONS OF CHRONIC LUNG DISEASES, AND REVERSAL OF STEROID RESISTANCE}

The immune system of $\mathrm{VDR}^{-/}$mice show heightened response to autoimmune diseases, such as inflammatory bowel disease or type I diabetes after exposure to relevant predisposing factors (Bouillon et al., 2008a,b). VDR ${ }^{-/-}$mice are more prone to develop chemocarcinogen-induced cancers including lung cancer (Bouillon et al., 2008b). These mice are also reported to develop high rennin hypertension, cardiac hypertrophy, and increased thrombogenicity (Rahman et al., 2007; Bouillon et al., 2008b), which are co-morbid conditions in COPD. In humans, toll-like receptor 9 (TLR9) modulates the function of $1,25(\mathrm{OH})_{2} \mathrm{D}_{3}$-induced IL-10 secreting $\mathrm{T}$ regulatory cells in vivo, thus highlighting the importance of vitamin D pathway regulation in immune function (Urry et al., 2009). Vitamin D has been shown to promote Tregs in the presence of dexamethasone (Barrat et al., 2002). Xystrakis et al. (2006) showed that vitamin D induces Tregs to secrete IL-10 in steroid resistant patients with impaired IL-10 induction by glucocorticoids. Another study demonstrated that vitamin D alters chemokine expression in human airway smooth muscle cells and also inhibits gene for steroid resistance, suggesting antiinflammatory effect of vitamin D which may have therapeutic role against steroid resistance in asthma (Banerjee et al., 2008). A recent study investigated the relationship between $25(\mathrm{OH}) \mathrm{D}$ levels in the blood and response to inhaled corticosteroids (ICS) in severe COPD patients revealed that $25(\mathrm{OH})$ D levels were not associated with variation in short-term $\mathrm{FEV}_{1}$ responses to ICS therapy (Kunisaki and Rector, 2011).

In patients with persistent asthma, higher vitamin $D$ levels have been linked with improved lung function, decreased airway hyperresponsiveness and improvement in response to glucocorticoids. Thus, appropriate supplementation of vitamin $D$ in patients with asthma may improve several physiopathological conditions associated with asthma severity and treatment response (Sutherland et al., 2010). It is also shown that COPD patients are at high risk of vitamin D insufficiency because of the less outdoor activity, increased steroid intake, as a result of impairment in renal dysfunction and low storage capacity in muscle and fat due to muscle wasting (Janssens et al., 2009). A recent report also recognized the association between VDR genotype polymorphism and quadriceps strength in COPD patients, suggesting the correlation of VDR in skeletal muscle impairment in COPD and other chronic diseases (Hopkinson et al., 2008). Furthermore, vitamin D supplementation reversed the muscle weakness demonstrating the role of vitamin D in skeletal muscle function (Hornikx et al., 2011). Studies from elderly patients revealed that vitamin D supplementation reduced the risk of falls, and suggested that vitamin D deficiency is linked to decline muscle performance and increase in falls among elderly patients treated with statins (Goldstein et al., 2009). Recent reports in COPD patients with long-term systemic glucocorticoids lead to increased risk for osteoporosis correlating with disease severity and low vitamin D levels (Franco et al., 2009). Several studies have shown the functional relevance of vitamin D-binding protein gene (GC) polymorphism associated with COPD (Schellenberg et al., 1998; Ohkura et al., 2006; Janssens et al., 2010; Newnham et al., 2010). Similarly, vitamin-D-binding protein (VDBP) gene polymorphisms have been shown in patients with asthma/COPD (Janssens et al., 2010; Newnham et al., 2010; Sathyamurthy et al., 2010; Shen et al., 2010), highlighting the alterations of overall axis of vitamin D/VDR/VDB in pathogenesis of chronic lung diseases and their co-morbid conditions (McGowan et al., 2010).

The mRNA levels of aging-related genes, such as NF-кB, fibroblast growth factor-23 (Fgf-23), p53, and insulin-like growth factor 1 receptor (IGF1R) are significantly decreased in older $\mathrm{VDR}^{-/-}$ mice suggesting that ablation of VDR promotes premature aging, cellular senescence, and vitamin $\mathrm{D}_{3}$ homeostasis is shown to regulate physiological aging (Keisala et al., 2009). It is not known whether the deficiency of vitamin D has any effect on stressinduced premature senescence/aging in smokers who develop COPD/emphysema. Vitamin D is implicated to play a key role in fetal lung growth, development, and maturation based on animal model and human studies (Litonjua, 2009). Evidence from the epidemiological studies also suggested that the higher prenatal uptake of vitamin $\mathrm{D}$ protected against childhood wheezing through its role in up-regulating antimicrobial peptides or due to its multiple immune effects (Litonjua, 2009). Vitamin D also has been shown to have a therapeutic potential in alteration of steroidmediated smooth muscle proliferation and airway remodeling (Clifford and Knox, 2009), which are seen in severe asthmatics and patients with COPD during exacerbations (Litonjua, 2009; Newnham et al., 2010; Tantisira et al., 2011). Vitamin D via VDR may recruit HDAC2/SIRT1 deacetylases in transrepressor complex leading to deacetylation of certain pro-inflammatory transcription factor, histones, and/or upregulation of anti-inflammatory cytokine IL-10 (Xystrakis et al., 2006; Urry et al., 2009). Hence, vitamin D/VDR may have a role in regulation of nuclear chromatin modifications.

\section{VITAMIN D AND EPIGENETIC MECHANISMS}

Histone tails are modified by an extensive group of nonhistone chromatin-associated proteins called chromatin modifying enzymes which exist in cells as multi-component protein complexes (Berger, 2002). These complexes are frequently recruited to nuclear chromatin in association with DNA-bound transcription factors, and play a vital role in genome management and stability. In response to environmental stresses, various covalent 
modifications in histones and associated regions of DNA occur by binding specific factors leading to alterations in the structural property of chromatin (Ruthenburg et al., 2007).

Histone modifications play a complex regulatory role in gene transcription, which is influenced by a wide variety of chromatin modification enzymes. The PTMs of histones include: acetylation by histone acetyltransferases (HATs), deacetylation by histone deacetylases (HDACs), phosphorylation by protein kinases, methylation by histone methyltransferases (HMTs), demethylation by histone demethylases (HDMs), and ubiquitination by ubiquitination enzymes (Figure 2). Histone modification enzymes, their structures, mechanism, and specificities are elaborately reviewed earlier (Marmorstein and Trievel, 2009). These PTMs may act alone or in concert to facilitate the activation or repression of chromatin-mediated gene expression for various inflammatory mediators, genes for cell cycle arrest, apoptosis, senescence, antioxidants, growth factors and tumor suppressor genes involved in COPD, and lung cancer (Berger, 2007; Guil and Esteller, 2009). Earlier reports suggest that specific modification make-up constitutes a "histone code," which is recognized via a "decoding machinery" comprised by modification-dependent, and chromatin-associated polypeptides (Strahl and Allis, 2000). The possible link for specific epigenetic modifications on proinflammatory genes in different disease phenotype might be due to the environment and alterations in gene expression patterns (Jirtle and Skinner, 2007).

Post-translational modifications of histones play a key role in epigenetic regulation of gene expression, and thus have important implication in environmentally-mediated chronic lung diseases, such as COPD and asthma (Seligson et al., 2009; Wang

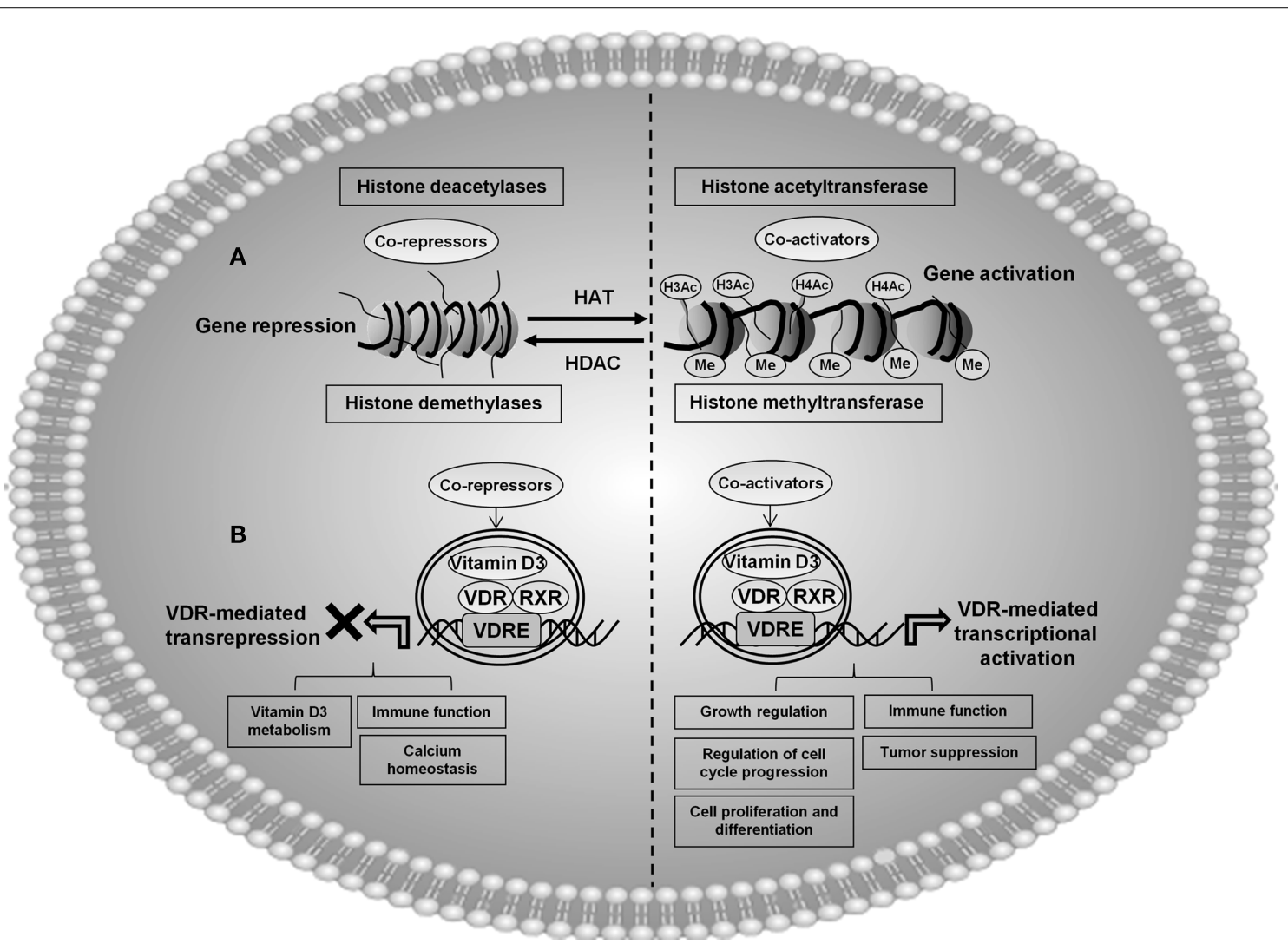

FIGURE 2 | A proposed model showing the possible involvement of vitamin D3 (1 $\alpha, 25$-dihydroxyvitamin D3)-mediated molecular epigenetic mechanisms in regulation of cellular and physiological processes. (A) General mechanism showing acetylation and deacetylation of histone by chromatin modification. Histone acetylation correlates with active gene transcription, and deacetylation associated with gene repression. Demethylases along with HATs are involved in gene activation, whereas histone trimethylation is often associated with gene repression. Vitamin D/NDR deregulation can potentially lead to epigenetic chromatin modifications on histones $\mathrm{H} 3$ and $\mathrm{H} 4$, which may be associated with epigenetic modifications in chronic diseases linked with vitamin D deficiency. (B) Vitamin $D$ receptor (VDR), exist as heterodimer with retinoid $X$ receptor (RXR), and this complex (VDR/RXR) binds to specific genomic sequences on the promoter regions of target genes (vitamin $\mathrm{D}$ response elements), and recruits transcription factors and co-regulatory molecules to activate or suppress gene transcription. Activation of VDR by different environmental agents along with other co-activator proteins can lead to histone acetylation culminating transcriptional regulation of a variety of genes involved in cellular and molecular functions, such as: regulation of cell cycle, immune function, cell proliferation and differentiation, growth regulation, and tumor suppression. VDR along with co-repressor complex results in transrepression of certain genes involved in vitamin D3 metabolism, immune function, and calcium homeostasis. Vitamin D and VDR may be one among the key epigenetic regulators along with chromatin modification enzymes involved in post-translational modification of histones in various chronic lung diseases. For example, VDR along with histone modification enzymes may be involved in acetylation, deacetylation, methylation, and demethylation, of different epigenetically regulated target genes. 
et al., 2009). Since histones are post-translationally modified during disease progression, the identification of these patterns is important for the understanding of human epigenetic marks in disease conditions. The majority in histone modifications are acetylation and methylation, which correlates with open chromatin and active gene transcription or repression (Strahl and Allis, 2000). Abnormalities in acetylation and methylation patterns on histones, resulting from imbalance of histone acetyltransferases/deacetylases and HMTs/demethylases, are associated with alteration in gene expression (Barlesi et al., 2007; Barnes, 2009; Schwartz, 2010; Figure 2). However, the histone-wide/epigenome linking epigenetics and airways disease are largely unknown. There has been several studies supporting the fact that dietary factors contribute to modify epigenetic marks including the dietary factors intake in utero (Davis and Uthus, 2004; Mathers et al., 2010). Furthermore, dietary habits in humans, or in animals models using experimental strategies, such as feeding high fat, low protein or energy restricted diets have demonstrated to cause epigenetic alterations from in utero to adult life (Hass et al., 1993; Lillycrop et al., 2005; Brait et al., 2009; van Straten et al., 2010; Widiker et al., 2010). Diet-induced epigenetic changes and their involvement in human health including in utero by vitamin D metabolism are the interests of current research (Karlic and Varga, 2011; McKay and Mathers, 2011).

Various recent studies have shown the evidence that multifunctional enhancers regulate VDR gene transcription, and $1,25(\mathrm{OH})_{2} \mathrm{D}_{3}$ induce the accumulation of VDR and up-regulate histone $\mathrm{H} 4$ acetylation at conserved regions in the human VDR gene (Zella et al., 2010). VDR/RXR dimer interacts with transcriptional co-activators, such as the HATs to regulate transcription (Fujiki et al., 2005). Vitamin D, VDR, and other nuclear receptors (RXR and GR) interact with other epigenetically regulated nuclear receptors mediating specific response to nutrients and metabolism (Karlic and Varga, 2011). Ligand-dependent HDACcontaining complex binds with relB promoter and VDR in dendritic cells (DC). Experimental evidence showed that HDAC3 is involved in negative regulation of $\mathrm{relB}$ in $\mathrm{DC}$ stimulated with LPS resulting in dissociation of VDR/HDAC3 from the relB promoter. This demonstrates the importance of vitamin D-mediated chromatin remodeling in regulation of DC function (Dong et al., 2005). Epigenetic role of $1,25(\mathrm{OH})_{2} \mathrm{D}_{3}$-mediated IL-12B repression was demonstrated by the quantitative ChIP assay. VDR and its partner RXR ligand recruits co-repressor complex [NCoR2/silent mediator for retinoid and thyroid hormone receptors (SMRT)] along with HDAC3 resulting in decreased acetylation of histone $\mathrm{H} 4$ and increased trimethylation of histone $\mathrm{H} 3$ (H3K27me3) on the IL-12B promoter and its transcription start site (TSS; Gynther et al., 2011). Recently, An et al. (2010) showed that VDR interacts with FOXO (Forkhead box $\mathrm{O}$ ) proteins and its regulator SIRT1, and 1,25D and stimulates SIRT1- and phosphatasedependent dephosphorylation and activation of FOXO protein function. FOXOs have been shown to be regulated by VDR (An et al., 2010). Calcitriol-mediated activation of VDR further augments the recruitment of FOXO3A and FOXO4 to the promoters of VDR target genes (An et al., 2010). Additionally, FOXO proteins also interact with other epigenetic regulators, such as SIRT1 (Voelter-Mahlknecht and Mahlknecht, 2010). VDR inhibits NF-кB function through SIRT1 and 1,25D signaling, suggesting the role of $1,25 \mathrm{D}$-mediated deacetylation of NF- $\kappa \mathrm{B}$ through its interaction with SIRT1 (Lavu et al., 2008). This may have implications in epigenetic regulation of steroid resistance and inflammatory response in patients with asthma and COPD where vitamin D insufficiency/deficiency occurs. In addition, this may play a role in epigenetic changes associated with vitamin D insufficiency/deficiency in addition to high methyl donor diet and environmental effects in utero which would result in susceptibility to chronic lung diseases later in adult life.

Vitamin D receptor and vitamin D regulate $\mathrm{p} 21^{\text {(waf1/cip1) }}$ gene which is involved in cell cycle arrest (Liu et al., 1996). A recent study showed that VDR induced regulation of $\mathrm{p} 21^{\text {(waf1/cip } 1)}$ expression and cell cycle arrest which is linked to VDR-governed feed-forward loop including interplay of histone modifications (H3K9ac and H3K27me3; Thorne et al., 2011). Another recent report provided the evidence that VDR-responsive genes, such as the tumor suppressor C/EBP, could be re-induced by treating the cells with 5'deoxy-azacytidine (AZA; Marik et al., 2010). The VDR-mediated positive and negative gene regulation by co-repressors [SMRT, NR co-repressors $(\mathrm{NCoR})]$, co-activators $[\mathrm{CBP} / \mathrm{p} 300$, steroid receptor co-activators (SRCs)], and chromatin remodeling complex (SWI/SNF) were reviewed earlier (Bouillon et al., 2008b; Karlic and Varga, 2011). These studies highlight the role of vitamin $\mathrm{D} / \mathrm{VDR}$ in regulation of epigenetic modifications on promoters of genes, such as $\mathrm{p} 21^{\text {(wafl/cipl) }}$ and C/EBP, and thereby regulating cellular senescence and differentiation. Hence, understanding the epigenetics of vitamin D and VDR on chromatin modifications and modulation of pro-inflammatory genes, cell cycle, and antimicrobial gene expression would provide knowledge for molecular epigenetic functions of vitamin D in management of chronic inflammatory lung diseases. This may be possible by understanding the epigenetic role of vitamin D and VDR in mouse models and evaluate the subsets of key histone modification marks caused in response to environmental exposures.

\section{FUTURE PERSPECTIVES OF EPIGENETIC-BASED VITAMIN D THERAPY IN CHRONIC LUNG DISEASES}

Vitamin D deficiency/insufficiency is an important global publichealth problem due to low serum levels of vitamin D either due to its low intake or reduced biosynthesis (Janssens et al., 2009). Epidemiological studies have suggested a strong correlation of low serum concentrations of 25-hydroxy vitamin D with decline in pulmonary function in susceptible population (asthma and COPD) exposed to environmental airborne particulates (Black and Scragg, 2005; Gilbert et al., 2009; Hughes and Norton, 2009; Kunisaki et al., 2011). A recent study on vitamin D status in patients with COPD who participate in pulmonary rehabilitation $(\mathrm{PR})$ revealed an association between vitamin $\mathrm{D}$ deficiency and higher dropout rates and smaller improvement in functional capacity. The potential relationship between vitamin D deficiency and muscle function in PR, however, are not known (Ringbaek et al., 2011). The beneficial effect of vitamin D based on its newly discovered action for therapeutic intervention in chronic lung disease and other health effects are reviewed earlier (Bikle, 2009, 2010; Clifford and Knox, 2009; Adams and Hewison, 2010; Rosen, 2011). 
Vitamin D and VDR regulate several cellular processes, such as inflammation, proliferation, senescence, differentiation, and apoptosis (Holick, 2007). Recent studies have highlighted the physiological implications of dietary vitamin $\mathrm{D}$ in improvement of innate immune and inflammatory responses against respiratory pathogens, opportunistic infections, and environmental agents (Wang et al., 2004; Holick and Chen, 2008; Herr et al., 2011; Zosky et al., 2011). The levels of VDR are significantly decreased in lung tissues of COPD patients (Sundar et al., 2011). VDR deficient/knockout mice developed COPD-phenotype implicating the role of VDR in pathogenesis of chronic lung diseases (Sundar et al., 2011). Several studies have also highlighted the importance of vitamin D supplementation and VDR with steroid resistance and exacerbations in patients with COPD and asthma (Searing et al., 2010; Sutherland et al., 2010). Quint and Wedzicha (2010) in a recent editorial highlighted several distinct reports that link vitamin D deficiency and COPD. Furthermore, adequate clinical trials assessing specific clinical outcomes using vitamin D supplementations in COPD may facilitate in understanding the role of vitamin $\mathrm{D}$ in COPD and the mechanisms by which increasing vitamin $\mathrm{D}$ levels from the normal range would influence the natural history of COPD (Quint and Wedzicha, 2010). Current research on vitamin D is exciting, as the reports on vitamin D supplementation using animal models and human clinical trials start to unfold, and will shed light on the hidden molecular epigenetic regula-

\section{REFERENCES}

Adams, J. S., and Hewison, M. (2008). Unexpected actions of vitamin D: new perspectives on the regulation of innate and adaptive immunity. Nat. Clin. Pract. Endocrinol. Metab. 4, 80-90.

Adams, J. S., and Hewison, M. (2010). Update in vitamin D. J. Clin. Endocrinol. Metab. 95, 471-478.

Adorini, L., Penna, G., Giarratana, N., Roncari, A., Amuchastegui, S., Daniel, K. C., and Uskokovic, M. (2004). Dendritic cells as key targets for immunomodulation by vitamin D receptor ligands. J. Steroid Biochem. Mol. Biol. 89-90, 437-441.

An, B. S., Tavera-Mendoza, L. E., Dimitrov, V., Wang, X., Calderon, M. R., Wang, H. J., and White, J. H. (2010). Stimulation of Sirt1-regulated FoxO protein function by the ligandbound vitamin D receptor. Mol. Cell. Biol. 30, 4890-4900.

Banerjee, A., Damera, G., Bhandare, R., Gu, S., Lopez-Boado, Y., Panettieri, R. Jr., and Tliba, O. (2008). Vitamin $\mathrm{D}$ and glucocorticoids differentially modulate chemokine expression in human airway smooth muscle cells. Br. J. Pharmacol. 155, 84-92.

Barlesi, F., Giaccone, G., GallegosRuiz, M. I., Loundou, A., Span, S. W., Lefesvre, P., Kruyt, F. A., and Rodriguez, J. A. (2007). Global histone modifications predict prognosis of resected non small-cell lung cancer. J. Clin. Oncol. 25, 4358-4364.

Barnes, P. J. (2009). Targeting the epigenome in the treatment of asthma and chronic obstructive pulmonary disease. Proc. Am. Thorac. Soc. 6, 693-696.

Barnes, P. J., Shapiro, S. D., and Pauwels, R. A. (2003). Chronic obstructive pulmonary disease: molecular and cellular mechanisms. Eur. Respir. J. 22, 672-688.

Barrat, F. J., Cua, D. J., Boonstra, A., Richards, D. F., Crain, C., Savelkoul, H. F., De Waal-Malefyt, R., Coffman, R. L., Hawrylowicz, C. M., and O'Garra, A. (2002). In vitro generation of interleukin 10-producing regulatory CD4(+) T cells is induced by immunosuppressive drugs and inhibited by $\mathrm{T}$ helper type 1 (Th1)and Th2-inducing cytokines. J. Exp. Med. 195, 603-616.

Berger, S. L. (2002). Histone modifications in transcriptional regulation. Curr. Opin. Genet. Dev. 12, 142-148.

Berger, S. L. (2007). The complex language of chromatin regulation during transcription. Nature 447, 407-412.

Bikle, D. (2009). Nonclassic actions of vitamin D. J. Clin. Endocrinol. Metab. 94, 26-34.

Bikle, D. D. (2010). Vitamin D: newly discovered actions require reconsideration of physiologic

tory mechanisms of vitamin D and VDR in respiratory diseases. The research on role of vitamin $\mathrm{D}$ in regulation of epigenetics in various cellular functions is primitive, but will gain credence after the completion of several clinical trials that are currently in progress, testing the protective role of vitamin $\mathrm{D}$ in the prevention and treatment of chronic lung diseases, such as asthma and COPD (www.clinicaltrials.gov). Hence, studies on molecular epigenetic mechanisms of dietary vitamin $\mathrm{D}$ in lung cellular function (senescence, apoptosis, autophagy, proliferation, phagocytosis) and disease severity (immune-inflammatory responses, steroid resistance, host-defense) particularly in response to environmental agents would provide rationale in development of possible interventions in the management and prevention of chronic lung diseases and its susceptibility to exacerbations by dietary vitamin D supplementation (Lehouck et al., 2011). Understanding the key epigenetic mechanisms involved in vitamin D-mediated chromatin modifications (regulation of HDACs/SIRT1, histone acetylation/methylation/demethylation) would provide rationale for the epigenetic-based therapy by vitamin D supplementation in management and prevention of chronic lung diseases.

\section{ACKNOWLEDGMENTS}

This study was supported by the NIH 1R01HL085613, 1R01HL097751, 1R01HL092842, and NIEHS Environmental Health Sciences Center Grant ES-01247.

requirements. Trends Endocrinol. Metab. 21, 375-384.

Black, P. N., and Scragg, R. (2005). Relationship between serum 25hydroxyvitamin $\mathrm{D}$ and pulmonary function in the third national health and nutrition examination survey. Chest 128, 3792-3798.

Bouillon, R., Bischoff-Ferrari, H., and Willett, W. (2008a). Vitamin D and health: perspectives from mice and man. J. Bone Miner. Res. 23, 974-979.

Bouillon, R., Carmeliet, G., Verlinden, L., Van Etten, E., Verstuyf, A., Luderer, H. F., Lieben, L., Mathieu, C., and Demay, M. (2008b). Vitamin D and human health: lessons from vitamin D receptor null mice. Endocr. Rev. 29, 726-776.

Boyan, B. D., Wong, K. L., Fang, M., and Schwartz, Z. (2007). lalpha, 25(OH)2D3 is an autocrine regulator of extracellular matrix turnover and growth factor release via ERp60 activated matrix vesicle metalloproteinases. J. Steroid Biochem. Mol. Biol. 103, 467-472.

Brait, M., Ford, J. G., Papaiahgari, S., Garza, M. A., Lee, J. I., Loyo, M., Maldonado, L., Begum, S., Mccaffrey, L., Howerton, M., Sidransky, D., Emerson, M. R., Ahmed, S., Williams, C. D., and Hoque, M. O. (2009). Association between lifestyle factors and $\mathrm{CpG}$ island methylation in a cancer-free population. Cancer Epidemiol. Biomarkers Prev. 18, 2984-2991.

Cantorna, M. T. (2000). Vitamin D and autoimmunity: is vitamin $\mathrm{D}$ status an environmental factor affecting autoimmune disease prevalence? Proc. Soc. Exp. Biol. Med. 223, 230-233.

Caramori, G., Romagnoli, M., Casolari, P., Bellettato, C., Casoni, G., Boschetto, P., Chung, K. F., Barnes, P. J., Adcock, I. M., Ciaccia, A., Fabbri, L. M., and Papi, A. (2003). Nuclear localisation of p65 in sputum macrophages but not in sputum neutrophils during COPD exacerbations. Thorax 58, 348-351.

Chen, L. F., Williams, S. A., Mu, Y., Nakano, H., Duerr, J. M., Buckbinder, L., and Greene, W. C. (2005). NF-kappaB RelA phosphorylation regulates RelA acetylation. Mol. Cell. Biol. 25, 7966-7975.

Chishimba, L., Thickett, D. R., Stockley, R. A., and Wood, A. M. (2010). The vitamin $\mathrm{D}$ axis in the lung: a key role for vitamin D-binding protein. Thorax 65, 456-462.

Clifford, R. L., and Knox, A. J. (2009). Vitamin D - a new treatment for airway remodelling in asthma? $\mathrm{Br}$. J. Pharmacol. 158, 1426-1428.

Davis, C. D., and Uthus, E. O. (2004). DNA methylation, cancer susceptibility, and nutrient interactions. Exp. Biol. Med. (Maywood) 229, 988-995. 
De Batlle, J., Romieu, I., Anto, J. M., Mendez, M., Rodriguez, E., Balcells, E., Ferrer, A., Gea, J., RodriguezRoisin, R., and Garcia-Aymerich, J. (2009). Dietary habits of firstly admitted Spanish COPD patients. Respir. Med. 103, 1904-1910.

Dogan, M., Erol, M., Cesur, Y., Yuca, S. A., and Dogan, Z. (2009). The effect of 25-hydroxyvitamin D3 on the immune system. J. Pediatr. Endocrinol. Metab. 22, 929-935.

Dong, X., Lutz, W., Schroeder, T. M., Bachman, L. A., Westendorf, J. J., Kumar, R., and Griffin, M. D. (2005). Regulation of relB in dendritic cells by means of modulated association of vitamin $\mathrm{D}$ receptor and histone deacetylase 3 with the promoter. Proc. Natl. Acad. Sci. U.S.A. 102, 16007-16012.

Dusso, A. S. (2003). Vitamin D receptor: mechanisms for vitamin D resistance in renal failure. Kidney Int. Suppl. S6-S9.

Ferrari, M., Schenk, K., Papadopoulou, C., Ferrari, P., Carbonare, L. D., and Bertoldo, F. (2010). Serum 25-hydroxy vitamin D and exercise capacity in COPD. Thorax 66, 544-545.

Forrest, K. Y., and Stuhldreher, W. L. (2011). Prevalence and correlates of vitamin $\mathrm{D}$ deficiency in US adults. Nutr. Res. 31, 48-54.

Franco, C. B., Paz-Filho, G., Gomes, P. E., Nascimento, V. B., Kulak, C. A., Boguszewski, C. L., and Borba, V. Z. (2009). Chronic obstructive pulmonary disease is associated with osteoporosis and low levels of vitamin D. Osteoporos. Int. 20, 1881-1887.

Fujiki, R., Kim, M. S., Sasaki, Y., Yoshimura, K., Kitagawa, H., and Kato, S. (2005). Ligand-induced transrepression by VDR through association of WSTF with acetylated histones. EMBO J. 24, 3881-3894.

Gilbert, C. R., Arum, S. M., and Smith, C. M. (2009). Vitamin D deficiency and chronic lung disease. Can. Respir. J. 16, 75-80.

Ginde, A. A., Mansbach, J. M., and Camargo, C. A. Jr. (2009). Vitamin $\mathrm{D}$, respiratory infections, and asthma. Curr. Allergy Asthma Rep. 9, 81-87.

Goldstein, M. R., Mascitelli, L., and Pezzetta, F. (2009). Statin therapy, muscle function and vitamin D. QJM 102, 890-891.

Greenlee, K. J., Werb, Z., and Kheradmand, F. (2007). Matrix metalloproteinases in lung: multiple, multifarious, and multifaceted. Physiol. Rev. 87, 69-98.
Guil, S., and Esteller, M. (2009). DNA methylomes, histone codes and miRNAs: tying it all together. Int. J. Biochem. Cell Biol. 41, 87-95.

Gynther, P., Toropainen, S., Matilainen, J. M., Seuter, S., Carlberg, C., and Vaisanen, S. (2011). Mechanism of lalpha,25-dihydroxyvitamin $\mathrm{D}(3)$ dependent repression of interleukin12B. Biochim. Biophys. Acta 1813, 810-818.

Hansdottir, S., and Monick, M. M. (2011). Vitamin D effects on lung immunity and respiratory diseases. Vitam. Horm. 86, 217-237.

Hansdottir, S., Monick, M. M., Hinde, S. L., Lovan, N., Look, D. C., and Hunninghake, G. W. (2008). Respiratory epithelial cells convert inactive vitamin $\mathrm{D}$ to its active form: potential effects on host defense. J. Immunol. 181, 7090-7099.

Hansdottir, S., Monick, M. M., Lovan, N., Powers, L., Gerke, A., and Hunninghake, G. W. (2010a). Vitamin D decreases respiratory syncytial virus induction of NF-kappaBlinked chemokines and cytokines in airway epithelium while maintaining the antiviral state. J. Immunol. 184, 965-974.

Hansdottir, S., Monick, M. M., Lovan, N., Powers, L. S., and Hunninghake, G. W. (2010b). Smoking disrupts vitamin D metabolism in the lungs. Am. J. Respir. Crit. Care Med. 181, A1425.

Hass, B. S., Hart, R. W., Lu, M. H., and Lyn-Cook, B. D. (1993). Effects of caloric restriction in animals on cellular function, oncogene expression, and DNA methylation in vitro. Mutat. Res. 295, 281-289.

Herr, C., Greulich, T., Koczulla, R. A., Meyer, S., Zakharkina, T., Branscheidt, M., Eschmann, R., and Bals, R. (2011). The role of vitamin D in pulmonary disease: COPD, asthma, infection, and cancer. Respir. Res. 12, 31.

Hogg, J. C., Chu, F., Utokaparch, S., Woods, R., Elliott, W. M., Buzatu, L., Cherniack, R. M., Rogers, R. M., Sciurba, F. C., Coxson, H. O., and Pare, P. D. (2004). The nature of small-airway obstruction in chronic obstructive pulmonary disease. N. Engl. J. Med. 350, 2645-2653.

Holick, M. F. (2007). Vitamin D deficiency. N. Engl. J. Med. 357, 266-281.

Holick, M. F., and Chen, T. C. (2008). Vitamin D deficiency: a worldwide problem with health consequences. Am. J. Clin. Nutr. 87, 1080S-1086S.

Hopkinson, N. S., Li, K. W., Kehoe, A., Humphries, S. E., Roughton, M., Moxham, J., Montgomery, H., and Polkey, M. I. (2008). Vitamin D receptor genotypes influence quadriceps strength in chronic obstructive pulmonary disease. Am. J. Clin. Nutr. 87, 385-390.

Hornikx, M., Lehouck, A., Carremans, C., Mathieu, C., Muylaert, I., Barbier, V., Coosemans, I., Van Remoortel, H., Decramer, M., Troosters, T., and Janssens, W. (2011). Vitamin D supplementation during rehabilitation in patients with chronic obstructive pulmonary disease: an intervention study. Am. J. Respir. Crit. Care Med. 183, A2533.

Hughes, D. A., and Norton, R. (2009). Vitamin D and respiratory health. Clin. Exp. Immunol. 158, 20-25.

Janssens, W., Bouillon, R., Claes, B. Carremans, C., Lehouck, A., Buysschaert, I., Coolen, J., Mathieu, C. Decramer, M., and Lambrechts, D. (2010). Vitamin D deficiency is highly prevalent in COPD and correlates with variants in the vitamin $\mathrm{D}$ binding gene. Thorax 65, 215-220.

Janssens, W., Lehouck, A., Carremans C., Bouillon, R., Mathieu, C., and Decramer, M. (2009). Vitamin D beyond bones in chronic obstructive pulmonary disease: time to act. Am. J. Respir. Crit. Care Med. 179, 630-636.

Janssens, W., Mathieu, C., Boonen, S. and Decramer, M. (2011). "Vitamin $\mathrm{D}$ deficiency and chronic obstructive pulmonary disease: a vicious circle," in Vitamins and Hormones, ed. L. Gerald (New York, NY: Academic Press), 86, 379-399.

Jirtle, R. L., and Skinner, M. K. (2007). Environmental epigenomics and disease susceptibility. Nat. Rev. Genet. 8, 253-262.

Karlic, H., and Varga, F. (2011). Impact of vitamin D metabolism on clinical epigenetics. Clin. Epigenetics 2, 55-61.

Keisala, T., Minasyan, A., Lou, Y. R., Zou, J., Kalueff, A. V., Pyykko, I., and Tuohimaa, P. (2009). Premature aging in vitamin $\mathrm{D}$ receptor mutant mice. J. Steroid Biochem. Mol. Biol. 115 91-97.

Koli, K., and Keski-Oja, J. (1996). Vitamin D3 regulation of transforming growth factor-beta system in epithelial and fibroblastic cells relationships to plasminogen activation. J. Investig. Dermatol. Symp. Proc. 1, 33-38.

Kumar, T., Sadoughi, A., Kohn, N., Miller, R., Chandak, T., and Talwar, A. (2011). Vitamin D deficiency in advanced lung disease. Am. J. Respir. Crit. Care Med. 183, A2346.

Kunisaki, K. M., Niewoehner, D. E., Singh, R. J., and Connett, J. E.
(2011). Vitamin D status and longitudinal lung function decline in the lung health study. Eur. Respir. J. 37, 238-243.

Kunisaki, K. M., and Rector, T. S. (2011). Vitamin D and responses to inhaled fluticasone in severe chronic obstructive pulmonary disease. Int. J. Chron. Obstruct. Pulmon. Dis. 6, 29-34.

Lavu, S., Boss, O., Elliott, P. J., and Lambert, P. D. (2008). Sirtuins novel therapeutic targets to treat ageassociated diseases. Nat. Rev. Drug Discov. 7, 841-853.

Lehouck, A., Mathieu, C., Bouillon, R., Verhaegen, J., Van Eldere, J., Decallonne, B., Carremans, C., Baeke, F., Decramer, M., and Janssens, W. (2011). High doses of vitamin D for the treatment of COPD exacerbations: an intervention trial. Am. J. Respir. Crit. Care Med. 183, A5372.

Lillycrop, K. A., Phillips, E. S., Jackson, A. A., Hanson, M. A., and Burdge, G. C. (2005). Dietary protein restriction of pregnant rats induces and folic acid supplementation prevents epigenetic modification of hepatic gene expression in the offspring. $J$. Nutr. 135, 1382-1386.

Lin, R., and White, J. H. (2004). The pleiotropic actions of vitamin $\mathrm{D}$. Bioessays 26, 21-28.

Litonjua, A. A. (2009). Childhood asthma may be a consequence of vitamin D deficiency. Curr. Opin. Allergy Clin. Immunol. 9, 202-207.

Liu, M., Lee, M. H., Cohen, M., Bommakanti, M., and Freedman, L. P. (1996). Transcriptional activation of the Cdk inhibitor p 21 by vitamin D3 leads to the induced differentiation of the myelomonocytic cell line U937. Genes Dev. 10, 142-153.

Liu, P. T., Stenger, S., Li, H., Wenzel, L., Tan, B. H., Krutzik, S. R., Ochoa, M. T., Schauber, J., Wu, K., Meinken, C., Kamen, D. L., Wagner, M., Bals, R., Steinmeyer, A., Zugel, U., Gallo, R. L., Eisenberg, D., Hewison, M., Hollis, B. W., Adams, J. S., Bloom, B. R., and Modlin, R. L. (2006). Toll-like receptor triggering of a vitamin D-mediated human antimicrobial response. Science 311, 1770-1773.

Marik, R., Fackler, M., Gabrielson, E., Zeiger, M. A., Sukumar, S., Stearns V., and Umbricht, C. B. (2010). DNA methylation-related vitamin D receptor insensitivity in breast cancer. Cancer Biol. Ther. 10, 44-53.

Marmorstein, R., and Trievel, R. C. (2009). Histone modifying enzymes: structures, mechanisms, and specificities. Biochim. Biophys. Acta 1789, 58-68. 
Mathers, J. C., Strathdee, G., and Relton, C. L. (2010). Induction of epigenetic alterations by dietary and other environmental factors. Adv. Genet. 71, 3-39.

McGowan, L. A., Wood, A. M., Newby, P., and Naidu, B. (2010). The role of the vitamin $\mathrm{D}$ axis in lung cancer. Thorax 65, A42-A43

McKay, J. A., and Mathers, J. C. (2011). Diet induced epigenetic changes and their implications for health. Acta Physiol. 202, 103-118.

Newnham, M., Carter, R., Sapey, L., Stockley, R. A., and Wood, A. M. (2010). Vitamin D binding protein in COPD exacerbations. Thorax 65, A126.

Nuttall, R. K., Sampieri, C. L., Pennington, C. J., Gill, S. E., Schultz, G. A., and Edwards, D. R. (2004). Expression analysis of the entire MMP and TIMP gene families during mouse tissue development. FEBS Lett. 563, 129-134.

Ohkura, K., Nagasawa, H., Uto, Y., Okamura, N., Murakami, A., and Hori, H. (2006). The role of Gc protein oligosaccharide structure as a risk factor for COPD. Anticancer Res. 26, 4073-4078.

Quint, J. K., and Wedzicha, J. A. (2010). Is vitamin $\mathrm{D}$ deficiency important in the natural history of COPD? Thorax 65, 192-194.

Rahman, A., Hershey, S., Ahmed, S., Nibbelink, K., and Simpson, R. U. (2007). Heart extracellular matrix gene expression profile in the vitamin D receptor knockout mice. J. Steroid Biochem. Mol. Biol. 103, 416-419.

Rajendrasozhan, S., Chung, S., Sundar, I. K., Yao, H., and Rahman, I. (2010). Targeted disruption of NF\{kappa\}B1 (p50) augments cigarette smoke-induced lung inflammation and emphysema in mice: a critical role of p50 in chromatin remodeling. Am. J. Physiol. Lung Cell Mol. Physiol. 298, L197-L209.

Rajendrasozhan, S., Yang, S. R., Kinnula, V. L., and Rahman, I. (2008). SIRT1, an antiinflammatory and antiaging protein, is decreased in lungs of patients with chronic obstructive pulmonary disease. Am. J. Respir. Crit. Care Med. 177, 861-870.

Razzaque, M. S., Sitara, D., Taguchi, T., St-Arnaud, R., and Lanske, B. (2006). Premature aging-like phenotype in fibroblast growth factor 23 null mice is a vitamin $\mathrm{D}$-mediated process. FASEB J. 20, 720-722.

Ringbaek, T., Martinez, G., Durakovic, A., Thøgersen, J., Midjord, A.-K., Jensen, J.-E. B., and Lange, P. (2011).
Vitamin D status in patients with chronic obstructive pulmonary disease who participate in pulmonary rehabilitation. J. Cardiopulm. Rehabil. Prev. 31, 261-267.

Rosen, C. J. (2011). Clinical practice. Vitamin D insufficiency. N. Engl. J. Med. 364, 248-254.

Ruthenburg, A. J., Li, H., Patel, D. J., and Allis, C. D. (2007). Multivalent engagement of chromatin modifications by linked binding modules. Nat. Rev. Mol. Cell Biol. 8, 983-994.

Sathyamurthy, R., Manney, S., Wood, A., Perkins, G., Webster, C., Krishna, M., and Mansur, A. (2010). P14 Does vitamin D Axis have an effect on the severity of asthma? Thorax 65, A82-A83.

Schellenberg, D., Pare, P. D., Weir, T. D., Spinelli, J. J., Walker, B. A., and Sandford, A. J. (1998). Vitamin D binding protein variants and the risk of COPD. Am. J. Respir. Crit. Care Med. 157, 957-961.

Schwartz, D. A. (2010). Epigenetics and environmental lung disease. Proc. Am. Thorac. Soc. 7, 123-125.

Searing, D. A., Zhang, Y., Murphy, J. R., Hauk, P. J., Goleva, E., and Leung, D. Y. (2010). Decreased serum vitamin $D$ levels in children with asthma are associated with increased corticosteroid use. J. Allergy Clin. Immunol. 125, 995-1000.

Seligson, D. B., Horvath, S., Mcbrian, M. A., Mah, V., Yu, H., Tze, S., Wang, Q., Chia, D., Goodglick, L., and Kurdistani, S. K. (2009). Global levels of histone modifications predict prognosis in different cancers. Am. J. Pathol. 174, 1619-1628.

Shaheen, S. O., Jameson, K. A., Robinson, S. M., Boucher, B. J., Syddall, H. E., Aihie Sayer, A., Cooper, C., Holloway, J. W., and Dennison, E. M. (2011). Relationship of vitamin $\mathrm{D}$ status to adult lung function and COPD. Thorax 66, 692-698.

Shen, L. H., Zhang, X. M., Su, D. J., Yao, S. P., Yu, B. Q., Wang, H. W., and Lu, F. Z. (2010). Association of vitamin D binding protein variants with susceptibility to chronic obstructive pulmonary disease. J. Int. Med. Res. 38, 1093-1098.

Simpson, R. U., Hershey, S. H., and Nibbelink, K. A. (2007). Characterization of heart size and blood pressure in the vitamin D receptor knockout mouse. J. Steroid Biochem. Mol. Biol. 103, 521-524.

Strahl, B. D., and Allis, C. D. (2000). The language of covalent histone modifications. Nature 403, 41-45.
Sun, J., Kong, J., Duan, Y., Szeto, F L., Liao, A., Madara, J. L., and Li, Y. C. (2006). Increased NFkappaB activity in fibroblasts lacking the vitamin $\mathrm{D}$ receptor. Am. J. Physiol. Endocrinol. Metab. 291, E315-E322.

Sundar, I. K., Hwang, J. W., Wu, S. Sun, J., and Rahman, I. (2011). Deletion of vitamin $\mathrm{D}$ receptor leads to premature emphysema/COPD by increased matrix metalloproteinases and lymphoid aggregates formation. Biochem. Biophys. Res. Commun 406, 127-133.

Sutherland, E. R., Goleva, E., Jackson, L. P., Stevens, A. D., and Leung, D. Y. (2010). Vitamin D levels, lung function, and steroid response in adult asthma. Am. J. Respir. Crit. Care Med. 181, 699-704.

Tantisira, K. G., Kho, A., Sharma, S. Litonjua, A. A., and Weiss, S. T. (2011). Vitamin D: link between lung development and asthma susceptibility. Am. J. Respir. Crit. Care Med. 183, A1338.

Thorne, J. L., Maguire, O., Doig, C. L., Battaglia, S., Fehr, L., Sucheston, L. E., Heinaniemi, M., O’Neill, L. P., Mccabe, C. J., Turner, B. M., Carlberg, C., and Campbell, M. J. (2011). Epigenetic control of a VDR-governed feed-forward loop that regulates $\mathrm{p} 21$ (waf1/cip1) expression and function in nonmalignant prostate cells. Nucleic Acids Res. 39, 2045-2056.

Urry, Z., Xystrakis, E., Richards, D. F. Mcdonald, J., Sattar, Z., Cousins, D. J., Corrigan, C. J., Hickman, E., Brown, Z., and Hawrylowicz, C. M. (2009). Ligation of TLR9 induced on human IL-10-secreting Tregs by 1alpha,25-dihydroxyvitamin D3 abrogates regulatory function. $J$. Clin. Invest. 119, 387-398.

van der Strate, B. W., Postma, D. S., Brandsma, C. A., Melgert, B. N., Luinge, M. A., Geerlings, M. Hylkema, M. N., Van Den Berg, A., Timens, W., and Kerstjens, $\mathrm{H}$. A. (2006). Cigarette smoke-induced emphysema: a role for the B cell? Am. J. Respir. Crit. Care Med. 173, 751-758.

van Straten, E. M., Bloks, V. W., Huijkman, N. C., Baller, J. F., Van Meer, H., Lutjohann, D., Kuipers, F., and Plosch, T. (2010). The liver Xreceptor gene promoter is hypermethylated in a mouse model of prenatal protein restriction. Am. J. Physiol. Regul. Integr. Comp. Physiol. 298, R275-R282.

Voelter-Mahlknecht, S., and Mahlknecht, U. (2010). The sirtuins in the pathogenesis of cancer. Clin. Epigenetics 1 71-83.

Wang, T. T., Nestel, F. P., Bourdeau, V., Nagai, Y., Wang, Q., Liao, J., Tavera-Mendoza, L., Lin, R., Hanrahan, J. W., Mader, S., and White, J. H. (2004). Cutting edge: 1,25dihydroxyvitamin D3 is a direct inducer of antimicrobial peptide gene expression. J. Immunol. 173, 2909-2912.

Wang, Z., Schones, D. E., and Zhao, K. (2009). Characterization of human epigenomes. Curr. Opin. Genet. Dev. $19,127-134$.

White, J.H. (2008). Vitamin D signaling, infectious diseases, and regulation of innate immunity. Infect. Immun. 76, 3837-3843.

Widiker, S., Karst, S., Wagener, A., and Brockmann, G. A. (2010). High-fat diet leads to a decreased methylation of the Mc4r gene in the obese BFMI and the lean B6 mouse lines. J. Appl. Genet. 51, 193-197.

Wittke, A., Chang, A., Froicu, M., Harandi, O. F., Weaver, V., August, A., Paulson, R. F., and Cantorna, M. T. (2007). Vitamin D receptor expression by the lung microenvironment is required for $\max$ imal induction of lung inflammation. Arch. Biochem. Biophys. 460, 306-313.

Wittke, A., Weaver, V., Mahon, B. D., August, A., and Cantorna, M. T. (2004). Vitamin D receptordeficient mice fail to develop experimental allergic asthma. J. Immunol. 173, 3432-3436.

Wood, A. M., Bassford, C., Webster, D., Newby, P., Rajesh, P., Stockley, R. A., and Thickett, D. R. (2011) Vitamin D-binding protein contributes to COPD by activation of alveolar macrophages. Thorax 66, 205-210.

Wu, S., Liao, A. P., Xia, Y., Li, Y. C., Li, J. D., Sartor, R. B., and Sun, J. (2010a). Vitamin D receptor negatively regulates bacterial-stimulated NF-kappaB activity in intestine. Am. J. Pathol. 177, 686-697.

Wu, S., Xia, Y., Liu, X., and Sun, J. (2010b). Vitamin D receptor deletion leads to reduced level of IkappaBalpha protein through protein translation, protein-protein interaction, and post-translational modification. Int. J. Biochem. Cell Biol. 42, 329-336.

Xystrakis, E., Kusumakar, S., Boswell, S., Peek, E., Urry, Z., Richards, D. F., Adikibi, T., Pridgeon, C., Dallman, M., Loke, T. K., Robinson, D. S., Barrat, F. J., O'Garra, A., Lavender, P., Lee, T. H., Corrigan, C., and Hawrylowicz, C. M. (2006). 
Reversing the defective induction of IL-10-secreting regulatory $\mathrm{T}$ cells in glucocorticoid-resistant asthma patients. J. Clin. Invest. 116, 146-155.

Yang, S. R., Wright, J., Bauter, M., Seweryniak, K., Kode, A., and Rahman, I. (2007). Sirtuin regulates cigarette smoke-induced proinflammatory mediator release via RelA/p65 NF-kappaB in macrophages in vitro and in rat lungs in vivo: implications for chronic inflammation and aging. Am. J. Physiol. Lung Cell Mol. Physiol. 292, L567-L576.

Yao, H., Edirisinghe, I., Rajendrasozhan, S., Yang, S. R., Caito, S., Adenuga,
D., and Rahman, I. (2008). Cigarette smoke-mediated inflammatory and oxidative responses are straindependent in mice. Am. J. Physiol. Lung Cell Mol. Physiol. 294, L1174L1186.

Zella, L. A., Meyer, M. B., Nerenz, R. D., Lee, S. M., Martowicz, M. L., and Pike, J. W. (2010). Multifunctional enhancers regulate mouse and human vitamin $\mathrm{D}$ receptor gene transcription. Mol. Endocrinol. 24, 128-147.

Zosky, G. R., Berry, L. J., Elliot, J. G., James, A. L., Gorman, S., and Hart, P. H. (2011). Vitamin D deficiency causes deficits in lung function and alters lung structure. Am. J. Respir. Crit. Care Med. 183, 1336-1343.

Conflict of Interest Statement: The authors declare that the research was conducted in the absence of any commercial or financial relationships that could be construed as a potential conflict of interest.

Received: 09 June 2011; accepted: 10 August 2011; published online: 30 August 2011
Citation: Sundar IK and Rahman I (2011) Vitamin D and susceptibility of chronic lung diseases: role of epigenetics. Front. Pharmacol. 2:50. doi: 10.3389/fphar.2011.00050

This article was submitted to Frontiers in Respiratory Pharmacology, a specialty of Frontiers in Pharmacology.

Copyright (c) 2011 Sundar and Rahman. This is an open-access article subject to a non-exclusive license between the authors and Frontiers Media SA, which permits use, distribution and reproduction in other forums, provided the original authors and source are credited and other Frontiers conditions are complied with. 